\title{
SEIZURE'S OUTCOME AFTER CORTICAL RESECTIONS INCLUDING THE FACE AND TONGUE ROLANDIC AREAS IN PATIENTS WITH REFRACTORY EPILEPSY AND NORMAL MRI SUBMITTED TO SUBDURAL GRIDS' IMPLANTATION
}

\author{
Arthur Cukiert, Jose A. Buratini, Elcio Machado, Alcione Sousa, Joaquim Vieira, \\ Cassio Forster, Meire Argentoni, Cristine Baldauf, Leila Frayman
}

\begin{abstract}
Purpose: To study the seizure's outcome in patients with refractory epilepsy and normal MRI submitted to resections including the rolandic cortex. Methods: Four adult patients were studied. All patients had motor or somatosensory simple partial seizures and normal MRI and were submitted to subdural grids' implantation with extensive coverage of the cortical convexity ( 1 in the non-dominant and 3 in the dominant hemisphere). Results: ECoG was able to define focal areas of seizures' onset in every patient. All patients were submitted to resection of the face and tongue motor and sensitive cortex; two patients had resections including the perirolandic cortex and 2 had additional cortical removals. Three patients are seizures' free and one had a greater then $90 \%$ reduction in seizure frequency. Conclusion: Resections including the face and tongue rolandic cortex can be safely performed even within the dominant hemisphere.
\end{abstract}

KEY WORDS: epilepsy, surgery, outcome, subdural grids, rolandic cortex.

\begin{abstract}
Resultados cirúrgicos em pacientes portadores de epilepsia refratária e ressonância magnética normal submetidos a ressecções das áreas rolândicas da face e língua investigados por meio de eletrodos subdurais

RESUMO - Objetivo: Estudar o efeito na frequência de crises epilépticas de ressecções de cortex rolândico em pacientes com epilepsia refratária e ressonância normal. Material: Quatro pacientes epilépticos adultos foram estudados. Todos possuíam crises parciais simples motoras ou sensitivas e ressonância normal, e foram submetidos ao implante de eletrodos subdurais cobrindo extensamente a convexidade hemisférica (1 no hemisfério não-dominante e 3 no hemisfério dominante). Resultados: O ECoG foi capaz de definir áreas ictais focais em todos os pacientes. Todos os pacientes foram submetidos à ressecção das áreas da face e língua do cortex rolândico motor e sensitivo; em dois, o cortex perirolândico foi incluído na ressecção e em dois pacientes, outras ressecções corticais foram adicionadas. Três pacientes estão livres de crises e um obteve melhora maior que $90 \%$ da frequência de crises. Conclusão: Ressecções corticais envolvendo o cortex rolândico da língua e face podem ser realizadas com segurança mesmo no hemisfério dominante.
\end{abstract}

PALAVRAS-CHAVE: epilepsia, cirurgia, resultados, placas subdurais, córtex rolândico.

Cortical resections including the rolandic cortex have been rarely performed in patients with refractory epilepsy due to potential motor and speechrelated morbidity. This is especially true for patients without lesions demonstrated by magnetic resonance and dominant hemisphere epileptic foci'. Motor and somatosensitive simple partial seizures may arise from the rolandic cortex ${ }^{2-4}$. The rolandic cortex may originate epileptogenic or symptomatogenic zones and patients with normal MRI need invasive recordings to further delineate them. The adequate localization of the central sulcus is mandatory when planning surgical procedures within the rolandic cortex. Different techniques, such as evoked potentials, PET, magnetic transcranial stimulation, stimulation through chronically implanted subdural electrodes

Epilepsy Surgery Program, Hospital Brigadeiro and Clinica de Epilepsia de São Paulo, São Paulo SP, Brazil.

Received 28 February 2001, received in final form 6 June 2001. Accepted 13 June 2001.

Dr. Arthur Cukiert - Rua Dr. Alceu Campos Rodrigues 247/121 - 04544-000 São Paulo SP - Brasil. FAX: 551138463273.

E-mail: acukiert@uol.com.br 
and intraoperative direct cortical stimulation under local or general anesthesia, have already been used to map the motor cortex ${ }^{5-7}$. Subdural grids' implantation represents a safe and effective procedure allowing both cortical and neurophysiological mapping.

This paper describes the anatomical and neurophysiological data obtained from patients with refractory epilepsy and seizures arising in the rolandic areas submitted to extensive subdural grids' implantation.

\section{CASES}

All patients were investigated within the Epilepsy Surgery Program and gave formal consent for all surgical procedures.

Patient I. A right-handed 28 years-old man presented with daily motor simple partial seizures (SPS) initiating in the left side of the face and spreading to the left arm, with secondary tonic-clonic generalization, since the age of 4. Interictal electroencephalogram (EEG) showed widespread spiking over the right hemisphere. Ictal EEG showed diffuse background attenuation and no focal seizure's onset. MRI was normal. He was submitted to subdural grids' implantation (96 contacts) covering the whole right frontoparietooccipital convexity. Interictal electrocorticogram (ECoG) showed diffuse spiking over the right convexity. Ictal ECoG showed seizure's onset at the face rolandic motor region with early spread to the posterior frontal , anterior parietal and superior temporal gyri. Stimulation of the motor face cortex was able to reproduce the patient's typical seizure. Cortical resection including both sensory and motor tongue and face rolandic areas, the perirolandic cortex surrounding them and the superior temporal cortex was performed. Pathological examination showed mild gliosis. There was a transient (2 weeks) left facial paresis. He has had no SPS and one tonic-clonic seizure every 6 months since surgery (follow-up time $=24$ months).
Patient II. A right-handed 23 years-old man presented with daily motor SPS involving the right side of the face associated to aphasic blockage, since the age of 5. Interictal EEG showed widespread left hemispheric spiking and ictal EEG showed seizures characterized by diffuse spiking over the frontoparietooccipital convexity. MRI was normal. He was submitted to subdural grids' implantation covering the frontoparietooccipital convexity (96 contacts). Interictal ECoG showed diffuse spiking over the left convexity. Ictal ECoG showed that seizures started within the left tongue and face motor and sensory areas (Fig 1). Stimulation of the tongue motor area was able to reproduce the patient's typical seizure. He was submitted to resection restricted to the rolandic face and tongue areas (Fig 2). Pathological examination showed severe gliosis. There was a transient ( 2 weeks) right facial paresis and dysphasia (preserved comprehension, low verbal output and word finding difficulties). He has been seizure-free since surgery (follow-up time $=18$ months).

Patient III. A right-handed 24 years-old man, presented with daily motor SPS involving the right side of the face associated to aphasic blockage and eventually evolving to complex partial seizures without automatisms, since the age of 3. Interictal EEG showed diffuse spiking over the left convexity. Ictal EEG showed a large left frontotemporal area of seizure's onset. MRI was normal. He was submitted to subdural grids' implantation covering the left convexity (96 contacts). Interictal ECoG showed diffuse frontoparietal spiking. Ictal ECoG showed seizures starting over the left motor and sensory face cortex and from the anterior and posterior perirolandic cortex (Fig 3). Stimulation of the face sensory cortex was able to reproduce the patient's typical seizure. A cortical resection including the face and tongue sensory-motor areas and perirolandic cortex was performed. Pathological examination showed cortical dysplasia. There was a transient (1 week) right facial paresis and dysphasia (similar to Patient II). He has been seizure-free since surgery (follow-up time $=15$ months).

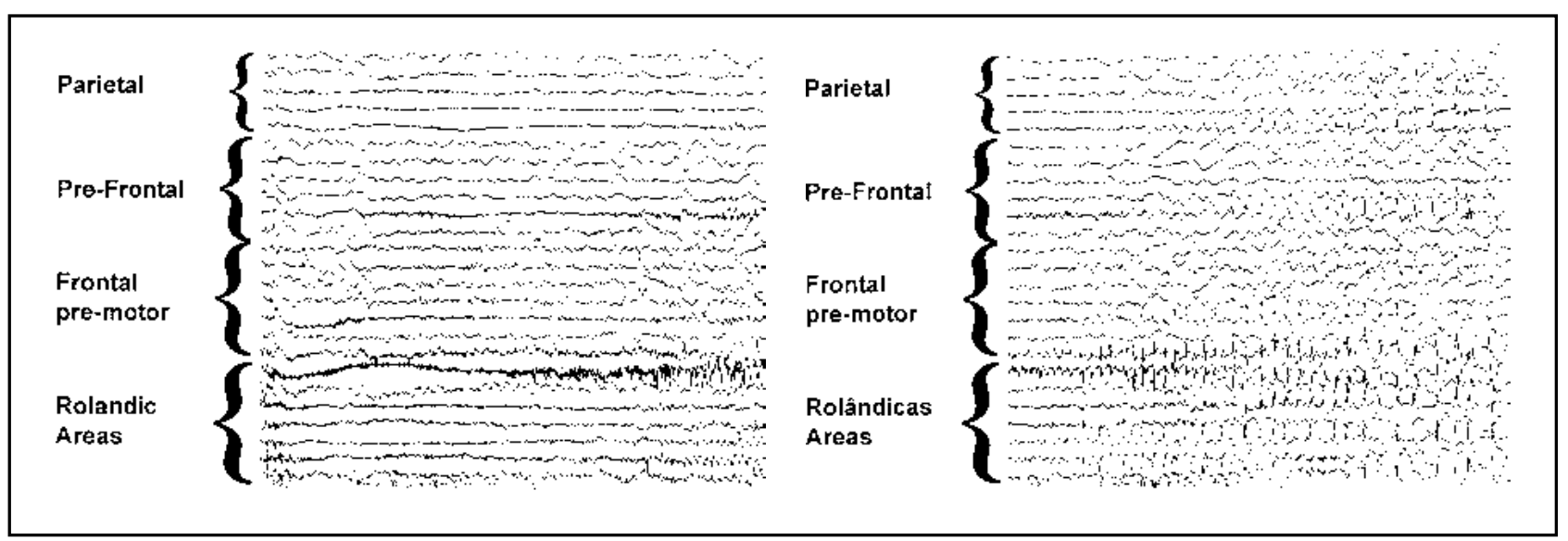

Fig 1. Left: ECoG sample obtained from Patient II showing focal ictal onset over the lower banks of the rolandic cortex. Right: ECoG sample showing the spread of this epileptic activity within the rolandic and perirolandic cortex. 


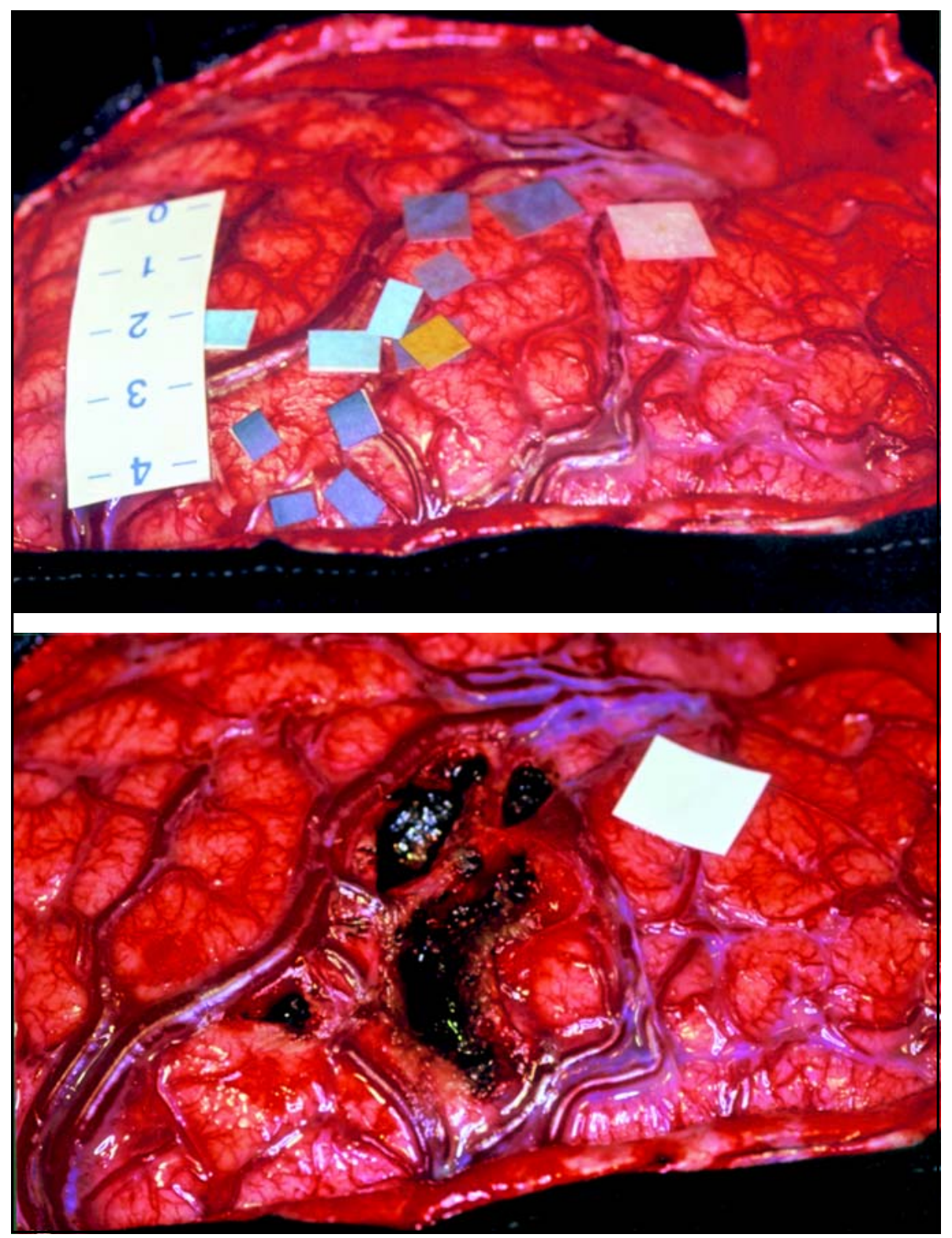

Fig 2. Above: Patient II's intraoperative view of the exposed brain convexity with superimposed neurophysiological data. Dark blue tags: motor strip; Light blue tags: ECoG ictal onset; Yellow tag: typical seizure triggered by cortical stimulation; White tag: Broca's area. Ruler in centimeters. Parasagittal cortex is seen at the bottom; frontal lobe to the right and parietal lobe to the left. The temporal lobe is seen superiorly. Below: Postresection view. A subpial removal of the motor and sensitive tongue and face cortex was performed.
Patient IV. A right-handed 20 years-old man presented with daily motor SPS involving the right side of the face and aphasic blockage, frequently evolving to complex partial seizures with bimanual automatisms, since the age of 3. Interictal and ictal EEG showed left frontoparietal spiking and seizure's onset, respectively. MRI was normal. He was submitted to subdural grids' implantation covering the frontoparietal convexity (96 contacts). Interictal ECoG showed widespread frontoparietal spiking. Ictal ECoG showed seizure's onset over the left face and tongue sensorimotor areas with very early spread to the posterior superior frontal gyrus. Stimulation of the face motor area was able to trigger the patient's typical seizure. He was submitted to resection of the left rolandic cortex related to the face and tongue and of the posterior two-thirds of the superior frontal gyrus. Pathological examination disclosed gliosis. There was a transient ( 2 weeks) right facial paresis and dysphasia (similar to Patient II). He has been seizure-free since surgery (follow-up time $=20$ months).

A summary of the resections' topography can be found in Figure 4.

\section{DISCUSSION}

Three out of the four patients in this series have been submitted to dominant hemisphere resections. Despite the potential speech-related morbidity, patients recovered extremely well after a mean of two weeks. The absence of long-lasting speech disturbances in these patients might be related to the careful subpial intragyral resection and preservation of the intrasulcal vessels and of the deeper fibers belonging to the arcuate and uncinate fasciculi.

All the patients had focal motor seizures and widespread interictal spiking areas, much larger then 


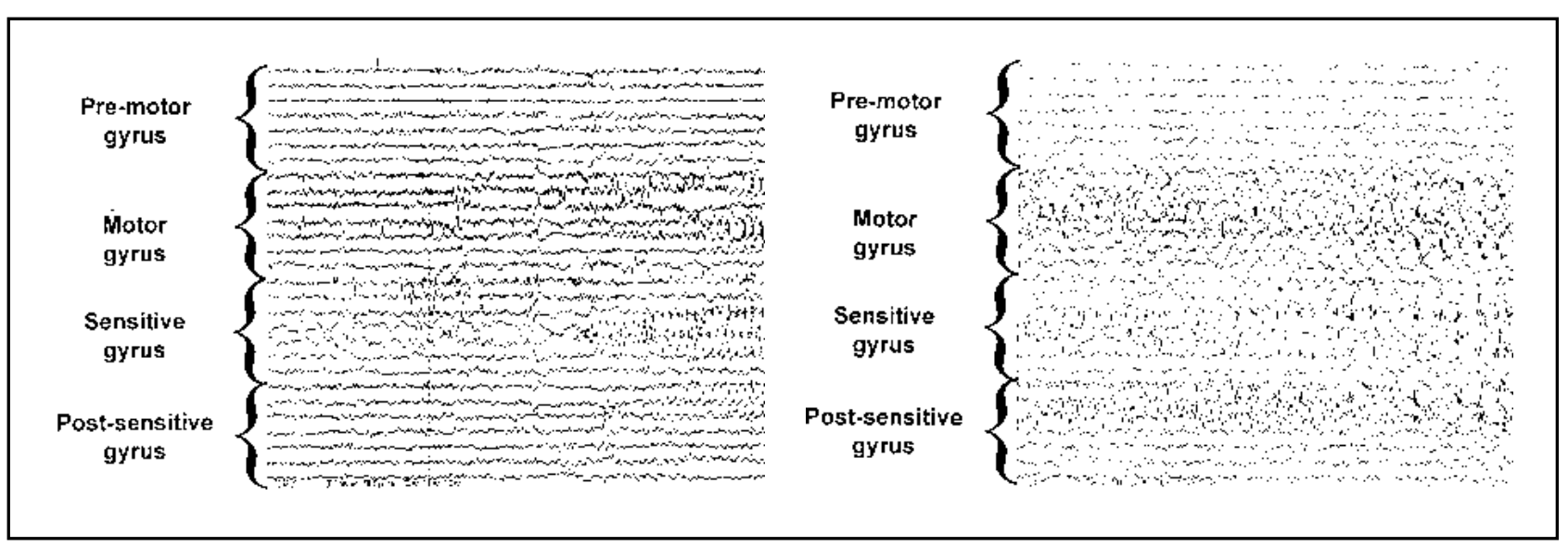

Fig 3. Left: ECoG sample obtained from Patient III showing ictal onset over the somatosensitive gyrus. Right: ECoG sample showing the spread of this activity within the rolandic and perirolandic cortex.

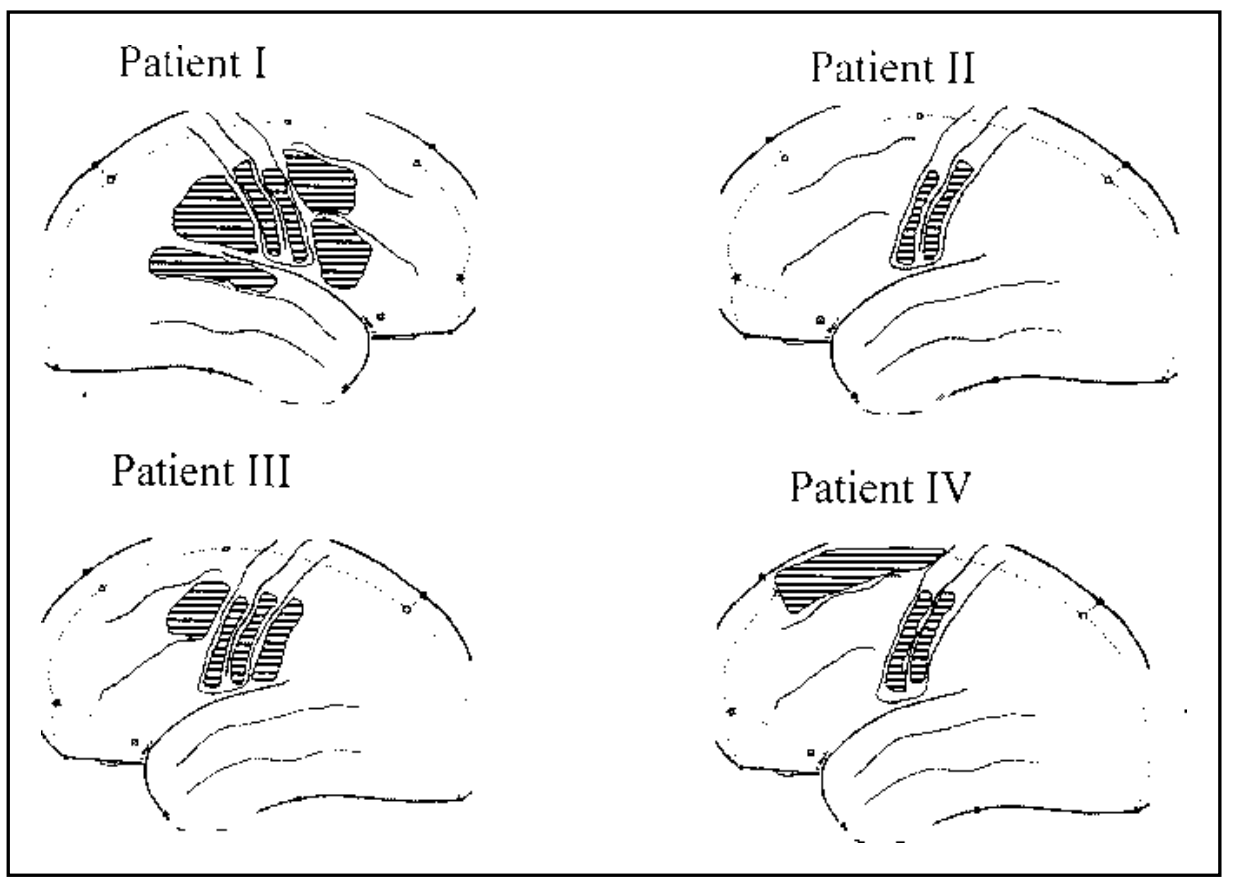

Fig 4. Summary of the topography of the resections performed in this series. the ictal or symptomatogenic zones. The actual resections included both the ictal onset and symptomatogenic zones whenever possible, but large interictally spiking areas were left behind. The latter might represent a more widespread epileptogenesis and might correlate to residual seizures, as seen in $\mathrm{Pa}$ tient I, who had a marked decrease in seizure's frequency but still presents sporadic tonic-clonic seizures.

Three of our four patients have been rendered seizure-free by surgery. Restricted cortical resections within the rolandic and perirolandic cortex proved to be effective even in the presence of large interictally spiking areas, as was also noted by Lehman et $\mathrm{al}^{8}$. In our series, ictal spread from the rolandic cor- tex occurred predominantly to the perirolandic cortex although early spreading to the superior temporal and superior frontal gyri was also seen. Cortical areas involved in the early spread of ictal activity should also be included in the resection if feasible. Resections were limited basically by the hand motor (not the sensitive) cortex, Broca's and Wernicke's areas and critical draining veins.

Pathological examination showed that one patient had cortical dysplasia ${ }^{9}$ not demonstrated preoperatively by high-resolution MRI, but gliosis was the main pathological substrate in these patients. Cortical dysplasia that do not cause distortion of the gray/white matter interface and anatomy might not be diagnosed with the current MRI technology. 
Non-invasive neurophysiological data were nonlocalizatory in all patients in this series and invasive recordings were needed for adequate neurophysiological and anatomical mapping of potentially resectable cortex ${ }^{10,11}$. Subdural grids seem to be superior to depth electrodes for the mapping of large superficial cortical areas located over the brain convexity.

\section{REFERENCES}

1. Holtzman RNN, Mark MH, Wiener LM, Minzer L. Lingual epilepsy: a case report of an unusual expression of focal cerebral discharge. J Neurol Neurosurg Psychiatry 1984;47:317-318.

2. Jabbari B, Coker SB. Paroxyxmal, rhytmic lingual movements and chronic epilepsy. Neurology 1981;31:1364-1367.

3. Neufeld MY, Blumen SC, Nisipeanu P, Korczyn AD. Lingual Seizures. Epilepsia 1988;29:30-33.
4. King RB, Schell MD. Cortical localization and monitoring during cerebral operations. J Neurosurg 1987;67:210-219.

5. LeRoux PD, Berger MS, Haglund MM, Pilcher WH, Ojemann GA. Resection of intrinsic tumors from nondominant face motor cortex using stimulation mapping: report of two cases. Surg Neurol 1991;36:44-48.

6. Wood CC, Spencer DD, Allison T, McCerthy G. Williamsin PD, Goff WR. Localization of human sensorimotor cortex during surgery by cortical surface recording of somatosensory evoked potentials. J Neurosurg 1988;68:99-111.

7. Picard C, Olivier A. Sensory cortical tongue representation in man. J Neurosurg 1983;59:781-789.

8. Lehman R, Andermann F, Olivier A, Tandon PN, Quesnay LF Rasmussen TB. Seizures with onset in the sensorimotor face area: clinical patterns and results of surgical treatment in 20 patients. Epilepsia 1994;35:1117-1124.

9. Kuzniecky R, Morawetz R, Faught E, Black L. Frontal and central lobe focal dysplasia: clinical, EEG and imaging features. Dev Med Childs Neurol 1995;37:159-166.

10. Gregoire EM, Goldring MD. Localization of function in the excision of lesions from the sensorimotor region. J Neurosurg 1984;61:1047-1054.

11. Uematsu S, Lesser R, Fisher R, et al. Resection of the epileptogenic area in critical cortex with the aid of a subdural electrode grid. Stereotact Funct Neurosurg 1990;55:34-45. 